\title{
LETRAMENTO E SENSIBILIDADE: EXPERIÊNCIAS E LABORATÓRIO DE LEITURA E IDENTIDADE NO AMBIENTE ESCOLAR
}

\author{
Paulo Cezar Maia \\ Universidade Federal do Rio de Janeiro \\ paulomacae@gmail.com \\ Daniele Oliveira Rosa \\ Universidade Federal do Rio de Janeiro \\ oliveirarosadaniele@gmail.com
}

\begin{abstract}
RESUMO
Um dos persistentes temas abordados em pesquisas sobre a escola é a falta ou a dificuldade de leitura dos estudantes brasileiros. O baixo desempenho nas avaliações externas revela a necessidade de se buscar um caminho para melhorar o trabalho nas escolas, garantindo ao aluno o aprendizado pleno. $\mathrm{O}$ que se pretende através deste artigo é apresentar um projeto de pesquisa que vem sendo desenvolvido em escolas do ensino básico no Estado do Rio de Janeiro, com objetivo de formar leitores de Literatura por meio de oficinas de tradução intersemiótica, com base no trabalho como princípio educativo (MAIA, 2020). As oficinas geram um meio para alfabetizar seus leitores e ao mesmo tempo suas sensibilidades. Essas oficinas trazem como resultado o engajamento do estudante à medida que ele utiliza os recursos tecnológicos populares em seu cotidiano e o estimula a observar, interpretar, analisar e produzir roteiros por meio da tradução do texto literário. As transposições de linguagem têm gerado também uma potência criativa, o que contribui para a autonomia dos estudantes. Por fim, vale destacar o caráter coletivo dos ambientes gerados nas oficinas, nas quais a literatura fornece possibilidades de compreensão e criação em uma perspectiva multidisciplinar que contribui para a melhoria da educação e transformação social.
\end{abstract}

Palavras-chaves: Leitura. Literatura. Educação e Trabalho politécnico.

\section{REPRESENTACIÓN DEL LENGUAJE Y SENSIBILIDAD: EXPERIENCIAS Y LABORATORIO DE LECTURA Y IDENTIDAD EN EL AMBIENTE ESCOLAR}

\section{RESUMEN}

Uno de los persistentes temas abordados en pesquisas sobre la escuela es la falta o la dificultad de lectura de los estudiantes brasileños. El bajo desempeño en las evaluaciones externas revela la necesidad de buscarse un camino para mejorar el trabajo en las escuelas, garantizando al alumno el aprendizaje pleno. Lo que se pretende a través de este artículo es presentar un proyecto de investigación que ha sido desarrollado en escuelas de enseñanza básica del Estado del Rio de Janeiro, con objetivo de formar lectores de Literatura por medio de oficinas de traducción intersemiótica, con base en el trabajo como principio educativo (MAIA, 2020). Esas oficinas generan un medio para alfabetizar sus lectores y sus sensibilidades simultáneamente. Esas oficinas traen como resultado la participación del estudiante a medida que él utiliza los recursos tecnológicos populares en su cotidiano y lo estimula a observar, interpretar, analizar y producir guiones por medio de la traducción del texto literario. Las trasposiciones de lenguajes han generado también una potencia creativa, lo que contribuye para la autonomía de los estudiantes. Por fin, vale destacar el carácter colectivo de los ambientes generados en las 
oficinas, en las cuales la literatura fornece posibilidades de comprensión y creación en una perspectiva multidisciplinar que contribuye para la mejoría de la educación y transformación social.

Palabras-claves: Lectura. Literatura. Educación y Trabajo politécnico.

\title{
LITERACY AND SENSIBILITY: EXPERIENCES AND READING LABORATORY AND IDENTITY IN THE SCHOOL ENVIRONMENT
}

\begin{abstract}
One of the persistent themes approached in research about primary school is the lack or difficulty of reading by Brazilian students. The low performance in external evaluations reveals the need to search for a way to improve the work in schools, ensuring student's full learning. The aim of this article is to present a research project that has been developed in elementary schools in the State of Rio de Janeiro, with the main goal of training readers through Literature reading workshops, which propose intersemiotic translations of literary texts for the audiovisual, centered on polytechnic work with formative character as a participatory methodology (Maia, 2020). These workshops result in student engagement, as they use the technological resources that are part of their daily lives, and stimulate them through literary reading to observe, interpret, analyze and produce scripts to translate the text in a meaningful way. This creative power comes from the autonomy that this whole process allows. Therefore, the collective work environment in which literature provides possibilities for understanding and creating within a transdisciplinary perspective contributes to the improvement of education and social transformation.
\end{abstract}

Keywords: Reading. Literature. Education and Polytechnical Work

\section{LETTRE ET SENSIBILITÉ: EXPÉRIENCES ET LABORATOIRE DE LECTURE ET D'IDENTITÉ EN MILIEU SCOLAIRE}

\section{RÉSUMÉ}

L'un des thèmes persistants abordés dans la recherche scolaire est le manque ou la difficulté de lecture des étudiants brésiliens. La faible performance des évaluations externes révèle la nécessité de rechercher un moyen d'améliorer le travail dans les écoles, garantissant ainsi le plein apprentissage de l'élève. L'objectif de cet article est de présenter un projet de recherche qui a été développé dans les écoles élémentaires de l'État de Rio de Janeiro, dans le but de former des lecteurs de littérature à travers des ateliers de traduction intersémiotique, basés sur le travail comme principe. pédagogique (MAIA, 2020). Les ateliers fournissent un moyen d'éduquer vos lecteurs et leurs sensibilités en même temps. Ces ateliers suscitent l'engagement des étudiants car il utilise des ressources technologiques populaires dans sa vie quotidienne et l'encourage à observer, interpréter, analyser et produire des scripts à travers la traduction du texte littéraire. Les transpositions linguistiques ont également généré un pouvoir créatif, qui contribue à l'autonomie des étudiants. Enfin, il convient de souligner le caractère collectif des environnements générés dans les ateliers, dans lesquels la littérature offre des possibilités de compréhension et de création dans une perspective multidisciplinaire qui contribue à l'amélioration de l'éducation et à la transformation sociale.

Mots clés: Lecture. Littérature. Éducation et Travail polytechnique. 
[...] A necessidade de ficção se manifesta a cada instante; aliás, ninguém pode passar um dia sem consumi-la, ainda que sob a forma de palpite na loteria, devaneio, construção ideal ou anedota. E assim se justifica o interesse pela função dessas formas de sistematizar a fantasia, de que a literatura é uma das modalidades mais ricas. (CANDIDO, 2002, p. 83).

\section{O PROBLEMA DA LEITURA NA ESCOLA COM SEU CURRÍCULO E METODOLOGIA TRADICIONAL}

A Lei de Diretrizes e Bases da Educação Brasileira na seção III artigo 32 diz: "O ensino fundamental, com duração mínima de oito anos, obrigatório e gratuito na escola pública, terá por objetivo a formação básica do cidadão, mediante: o desenvolvimento da capacidade de aprender, tendo como meios básicos o pleno domínio da leitura, da escrita e do cálculo" (BRASIL, 1996). O PCN ${ }^{1}$ de Português diz que "a conquista da escrita alfabética não garante ao aluno a possibilidade de compreender e produzir textos em linguagem escrita. Essa aprendizagem exige o trabalho pedagógico sistemático" (BRASIL, 1997, p. 27). Esses documentos orientam a escola para um trabalho que objetive a formação de leitores. $\mathrm{Na}$ introdução do PCN de Português, a discussão do sucesso escolar é conduzida à questão da leitura na escrita. O que mostra que os índices brasileiros de repetência nas séries iniciais estão diretamente ligados à dificuldade que a escola tem de ensinar a ler e a escrever (ibid., p. 19). Cabe então um projeto em que práxis é contemplada por meio do trabalho como princípio educativo. Assim, a leitura se torna o caminho no qual os conhecimentos produzidos pelos alunos podem ser divulgados por eles.

Entendemos que existem múltiplas inteligências, que devem ser valorizadas e trabalhadas, visando um conhecimento sistemático que possibilite, junto com a escrita alfabética e a compreensão textual, o "empodimento" dos estudantes. O termo foi cunhado pelo educador Sebastião Rocha ${ }^{2}$, que utiliza uma tradução da palavra empowerment do inglês para ampliar a tradução que a palavra empoderamento não traduz. Trata-se do "nós pode" do

\footnotetext{
${ }^{1}$ PCN (Parâmetros curriculares nacionais): É uma base desenvolvida pelo governo Federal.

${ }^{2}$ Sebastião Rocha (conhecido como Tião) professor da Universidade Federal de Ouro Preto resolveu deixar a universidade para se tornar educador popular e fundou a instituição CPCD chamada por ele de guarda-chuva: "Criei uma instituição guarda-chuva para abrigar o meu desejo de aprender. E hoje ela pertence a um monte de gente que usa essa instituição como espaço de aprendizagem. E aprender é fazer perguntas. Perguntas que nos desafiem, que nos joguem para frente, que apontem soluções novas para os velhos problemas" (ROCHA, T. 2014. Espaços da Educação - Bienal de São Paulo).
} 
mineiro. Não é tomar o poder, mas perceber que é possível fazer algo. "Tião subverteu duas línguas ao mesmo tempo. Assim, podemos arriscar dizer que o "empodimento" age como uma forma de pensamento liminar duplamente articulado, porque reverte a subalternidade do conhecimento pelas perspectivas, tanto do inglês americano como do português brasileiro padrão" (SEVERO, 2016, p. 25). Uma pessoa dotada de "empodimento" se vê capaz de produzir qualquer coisa, pois percebe ao fazê-lo que as limitações não se tornam um fator de impedimento, porém de busca de um novo caminho e formação para a conquista pretendida. Assim, o que há de "empodimento" na metodologia tradicional?

Podemos observar que a metodologia clássica na escola básica é aquela de apresentação de conhecimentos e execução de exercícios para memorização dos conteúdos. A escola infelizmente tem reforçado há anos uma forma de ensino que a desqualifica enquanto espaço de aprendizagem e a torna um instrumento do sistema excludente. Essas metodologias "tradicionais" têm conseguido certos resultados, dentro de alguns objetivos que elas pretendem conquistar, mas não de forma plena e eficiente. Primeiro, se o objetivo é adquirir um conhecimento racional dando conta de conceitos, ela consegue inserir minimamente esses conhecimentos. Segundo, se o objetivo é alfabetização, aquisição da leitura alfabética e até da leitura de compreensão textual, ela muitas vezes dá conta de formar alguns leitores. Porém essa metodologia "tradicional” na qual a cópia e os cálculos matemáticos estão fora de contexto, constitui um grande referencial para a manutenção do analfabetismo funcional. Isso porque ela não instiga a descoberta com propostas que realmente interessem aos estudantes e, de forma dinâmica, os conduza ao aprendizado e letramento. Aqueles que tais objetivos alcançam chegam a eles de forma custosa, enfadonha e mecanicista durante o processo, pois como uma máquina de aquisição de conhecimento em série, essas metodologias pretendem garantir que o aluno obtenha uma educação instrumental.

Outro problema causado pelas metodologias ditas "tradicionais" é o engessamento para a leitura crítica. Uma vez que a leitura é vista somente como reprodução de outras leituras, sem a valorização das observações e colaborações do próprio leitor com suas vivências e compreensões de mundo. Neste momento, o que se consegue é a reprodução da educação bancária, que Paulo Freire (2019) afirma estar a serviço da desumanização e opressão e não da libertação, pois nesses métodos inferimos que a proposta é o ajustamento do homem ao mundo, controlando o seu pensar e a sua ação. Sendo necessário assim uma educação para libertá-lo possibilitando meios para refletir, pensar, criar, comunicar-se e transformar a sua situação de opressão. "A libertação autêntica, que é a humanização em processo, não é uma coisa que se 
deposita nos homens. Não é uma palavra a mais, oca, mitificante. É práxis, que implica a ação e a reflexão dos homens sobre o mundo para transformá-lo" (FREIRE, 2019, p. 93).

Contrapondo o objetivo bancário, esse artigo apresenta um projeto de pesquisa que busca ir na contramão da metodologia "tradicional". A análise faz um recorte sobre o segundo ciclo do ensino fundamental, observando o currículo desse nível de escolaridade e apresentando uma proposta metodológica para que os objetivos relacionados às habilidades de leitura e escrita sejam alcançados. Esses objetivos relacionados à prática educativa do ensino da Língua Portuguesa podem ser encontrados no PCN.

Garantir progressivamente que os alunos sejam capazes de:

- compreender o sentido nas mensagens orais e escritas de que é destinatário direto ou indireto, desenvolvendo sensibilidade para reconhecer a intencionalidade implícita e conteúdos discriminatórios ou persuasivos, especialmente nas mensagens veiculadas pelos meios de comunicação;

- ler autonomamente diferentes textos dos gêneros previstos para o ciclo, sabendo identificar aqueles que respondem às suas necessidades imediatas e selecionar estratégias adequadas para abordá-los;

- utilizar a linguagem para expressar sentimentos, experiências e ideias, acolhendo, interpretando e considerando os das outras pessoas e respeitando os diferentes modos de falar;

- utilizar a linguagem oral com eficácia, começando a adequá-la a intenções e situações comunicativas que requeiram o domínio de registros formais, o planejamento prévio do discurso, a coerência na defesa de pontos de vista e na apresentação de argumentos e o uso de procedimentos de negociação de acordos necessários ou possíveis;

- produzir textos escritos, coesos e coerentes, dentro dos gêneros previstos para o ciclo, ajustados a objetivos e leitores determinados;

- escrever textos com domínio da separação em palavras, estabilidade de palavras de ortografia regular e de irregulares mais frequentes na escrita e utilização de recursos do sistema de pontuação para dividir o texto em frases; - revisar seus próprios textos a partir de uma primeira versão e, com ajuda do professor, redigir as versões necessárias até considerá-lo suficientemente bem escrito para o momento. (BRASIL, 1997, p. 79-80).

Articulando os objetivos acima com a tabela abaixo formulada pela UNESCO para observar os níveis de alfabetização funcional de uma população, podemos perceber a importância de um projeto de leitura que discuta e busque um caminho metodológico participativo.

No ano de 2001, a UNESCO (Organização das Nações Unidas para a Educação, a Ciência e a Cultura) estabeleceu um conjunto de critérios comportamentais afim de mensurar, em 3 níveis, o grau de alfabetização funcional de um indivíduo. (KENEDY, 2018, p.87-88). 
QUADRO 1 - níveis de alfabetização funcional (confira UNESCO 2001).

\begin{tabular}{|l|l|}
\hline Nível & Compreensão apenas de títulos de textos e de frases curtas; dificuldades em realizar \\
1 & operações aritméticas básicas. \\
\hline $\begin{array}{l}\text { Nível } \\
2\end{array}$ & $\begin{array}{l}\text { Compreensão de textos curtos, limitada capacidade de extração de informações e } \\
\text { inabilidade de criar conclusões a respeito do que se lê; realização de operações } \\
\text { aritméticas básicas, mas persistentes dificuldades com operações matemáticas mais } \\
\text { complexas. }\end{array}$ \\
\hline $\begin{array}{l}\text { Nível } \\
3\end{array}$ & $\begin{array}{l}\text { Pleno domínio da leitura, da escrita, dos números e das operações matemáticas (das } \\
\text { mais básicas às mais complexas). }\end{array}$ \\
\hline
\end{tabular}

Fonte: Retirado de Kenedy (2018, p. 88).

Partindo da questão das demandas relativas ao letramento, o projeto propõe uma abordagem mais flexível do currículo, que se adapte à realidade e às necessidades do aluno e da comunidade escolar, o que não acontece com as metodologias nas quais os objetivos para o ensino de Língua Portuguesa são norteados pela ótica conteudista e não permitem relação com a identidade do aluno. Por outro lado, a metodologia que o projeto tem estudado e experimentado, é aquela que o aluno participa do próprio processo de construção do currículo. Essa metodologia o libertará de uma condição que nega suas potencialidades criativas e impede a leitura crítica. Esse trabalho libertário gera o que Paulo Freire identifica com a "crença no seu poder criativo" e o que Tião Rocha chama de "empodimento". Na perspectiva do trabalho libertário o projeto então direciona uma proposta de leitura iniciada quando o aluno se apropria da leitura, ou seja, se torna livre para recodificar o texto, assumindo uma espécie de coautoria, com novas ideias, sentimentos e sentidos. O trabalho de tradução intersemiótica garante autonomia ao estudante para o desenvolvimento de habilidades criativas de leitura e escrita, além de garantir também acesso às novas tecnologias para comunicação social e interação crítica com distintas redes sociais. A proposta é por uma compreensão da formação de leitores por meio do trabalho como princípio educativo.

Isto é: dada a crescente fragmentação do conhecimento em nossa civilização, os sistemas de ensino passaram mais a investir não na formação básica do ser humano, com todas as implicações sensoriais e sensíveis que isto acarreta, mas estritamente num tipo de profissional que, além de ser incentivado a se relacionar com o mundo no modo exclusivo da intelectualidade, ainda a utiliza na estreita forma de uma razão operacional, restrita e restritivamente. (DUARTE, 2000, p. 172).

Essa formação pelo trabalho acontece de forma plena, pois não descarta a inteligência dos movimentos, do fazer ligado à atividade motora que ativa os sentidos. Um trabalho não mais fragmentado com discriminação e hierarquização de profissões que ao se basearem em atividades braçais são categorizadas como menos valia. 


\section{UMA PROPOSTA DE METODOLOGIA PARTICIPATIVA COMO CAMINHO}

Diante do mapa que a metodologia "tradicional" vem apresentando, o projeto propõe como caminho a metodologia participativa para efetivar a formação de leitores, buscando através de um trabalho de tradução intersemiótica acionar o engajamento do aluno (MAIA, 2020). Tudo isso faz parte de um projeto de pesquisa do Mestrado Profissional ${ }^{3}$ no Núcleo Interdisciplinar para o Desenvolvimento Social, cuja demanda é uma dissertação e um produto técnico. A parceria com o Grupo de Educação Multimídia (GEM) ${ }^{4}$, laboratório que desenvolve metodologias participativas, tem contribuído com o desenvolvimento da pesquisa. Essa parceria permitiu assim a criação de um laboratório de leitura na Escola Municipal Professor Marcos Waldemar de Freitas Reis, no município de Niterói, denominado LIDE $^{5}$ (Laboratório Leitura e Identidade) no qual, oficinas criativas são desenvolvidas no segundo ciclo para que habilidades de leitura sejam trabalhadas dentro de uma perspectiva dialógica. Essas oficinas trabalham com o texto literário propondo aos alunos uma leitura descompromissada, em que ideias e interpretações são acolhidas e instigadas para uma reflexão dentro da sua realidade. Em seguida, é indicada uma organização do que foi lido e compreendido em forma de roteiro para que essa leitura, através do uso da tecnologia em forma de vídeo, se transforme num produto que possibilitará outras leituras. Essa metodologia pela qual o estudante, por meio de um trabalho de tradução de linguagens, se envolve em todo processo criativo traz um aprendizado significativo. A autonomia do estudante se instancia nas etapas do trabalho: leitura, elaboração do roteiro, produção de materiais e filmagens. Isso ratifica a hipótese de que uma proposta de trabalho por meio de uma tradução intersemiótica realizada segundo uma metodologia participativa é capaz de dar conta do problema da dificuldade e baixos índices de leitura que temos acompanhado atualmente na educação brasileira.

\footnotetext{
${ }^{3}$ Mestrado Profissional- O Programa de Pós-Graduação de Tecnologia para o Desenvolvimento Social (PPGTDS), está sediado no NIDES (Núcleo Interdisciplinar para o Desenvolvimento Social), órgão suplementar do Centro de Tecnologia (CT) da UFRJ. O PPGTDS tem uma única área de concentração, denominada "Tecnologia para o Desenvolvimento Social", que conta com três linhas de pesquisa: "GESTÃO PARTICIPATIVA", "TECNOLOGIA SOCIAL" e "TRABALHO E FORMAÇÃO POLITÉCNICA - área na qual desenvolvo minha pesquisa é Trabalho e formação politécnica.

${ }^{4}$ GEM - Este laboratório dedica-se, por meio de articulação entre extensão, ensino e pesquisa, ao desenvolvimento de metodologias participativas de ensino-aprendizagem, sobretudo nas áreas de estudo de linguagens, formando seus estudantes em ações de pesquisa e extensão teórico-práticas, como no Projeto Travessias: Palavra-Imagem, formação de leitores da literatura a partir do trabalho de tradução e adaptação literária para o cinema em escolas do ciclo básico.

5 LIDE- laboratório criado em 2019 na escola da rede de Niterói chamada, Escola Municipal Professor Marcos Waldemar de Freitas Reis, a qual sou professora regente. Esse laboratório faz parte do meu produto técnico no Mestrado profissional que faço como formação continuada no NIDES.
} 
Essa autonomia conquistada através da conscientização do sujeito é aquela mencionada na pedagogia de Paulo Freire (2019) a qual propõe um olhar para o estudante que possui um conhecimento, devendo ser ele valorizado e trabalhado. Propondo ao mesmo observar e avaliar as dificuldades, problemas e desafios buscando resolvê-los. E nada mais efetivo para solucionar um problema, do que envolver todos na mesma discussão. Isso permite convidar os estudantes para participarem do processo. "Não há, portanto, na teoria dialógica da ação, um sujeito que domina pela conquista e um objeto dominado. Em lugar disso, há sujeitos que se encontram para a pronúncia do mundo, para a sua transformação" (FREIRE, 2019, p. 227).

A partir dessa fala de Paulo Freire, podemos perceber o quão importante é para a educação trabalhar com metodologias participativas, porque elas caminham com essa teoria dialógica da ação. O modo como são operadas, partindo do diálogo que leva a propostas a serem desenvolvidas através de ações, visa transformar a realidade. Quando os estudantes são ouvidos e suas ideias, questionamentos e dificuldades são acolhidos, surge um movimento de elaboração de formas e modos que garantem o protagonismo no processo de aprendizagem. Assim, não é o que eu, enquanto educador, posso acrescentar de conhecimentos, mas sim, como posso proporcionar ferramentas para que o estudante de forma autônoma contribua com a produção de conhecimento.

Portanto, as metodologias participativas se baseiam no jogo e nas oficinas, pois chama todos os participantes para a ação. "Essas oficinas são de execução material de vários objetos e de aprendizado concreto" (GAGNEBIN, 2012, p. 150). No momento do jogo, surgem parcerias e envolvimento como num palco de teatro. Para Benjamin, os atores (em geral trabalhadores não atores) reunidos por Brecht dispunham de poucos utensílios em cena, o que lhes possibilitava adaptações criativas, improvisos e experimentação. É isso que Benjamin chama de Spielraum, conceituado por Jeanne Marie Gagnebin como: espaço de jogo, de brincar, de experimentar. Logo, a metodologia participativa busca oferecer esse espaço de experimentação, onde os atores do processo de aprendizagem experimentam possibilidades e vivem a transformação que geram ao participarem da criação do seu próprio conhecimento.

Experimentar a leitura é participar de um jogo em que todos os jogadores devem iniciar sem vantagens adicionais, mas com as peças necessárias para começar a partida. Essas peças são as habilidades leitoras que possibilitam, além da decifração alfabética, estabelecer inferências, construir o sentido a partir das referências e da mediação dos professores, contribuindo para uma intervenção na interpretação do texto, o experimentando. Então, esse jogo insere tanto o educando quanto o educador num espaço vazio, que gera possibilidades para 
o aprendizado. No caso da Literatura, nesses espaços, há possibilidade para recriar sentidos e novas expressões. Pessoa (2006) no seu livro "Desassossego" diz que a Literatura simula a vida e consiste num esforço para torná-la real. Logo, seria um simulacro da vida, pois quando lemos simulamos e nos apropriamos do que estamos lendo como real. Assim objetivo utilizar dessa proposta de experimentação para construir uma metodologia participativa que se pretende através de um trabalho coletivo formar leitores. Esse espaço vazio da experimentação e das brincadeiras possibilita a apropriação, a produção e o engajamento.

Essas possibilidades que os espaços vazios inauguram podem ser exemplificadas a partir de um texto clássico literário como o livro "As cidades invisíveis", de Ítalo Calvino (2011) Na obra, percebemos o quanto esses espaços vazios possibilitam uma leitura produtiva com reforço de significados já conhecidos e acréscimo de novos. Quando analisamos as personagens Kublai Khan, o imperador, e Marco Polo, o mensageiro, percebemos que eles falavam línguas incompreensíveis entre si, mesmo assim, a comunicação acontecia para os dois, porque, por meio dos vazios, as respostas, os desejos, as curiosidades e emblemas encontravam caminho para serem experimentados. No mesmo sentido, os gestos e as pantomimas, que Marco Polo utilizava para manter a comunicação, funcionavam também como um instrumento criativo de produção de novos sentidos por Kublai Khan.

Não se sabe se Kublai Khan acredita em tudo o que diz Marco Polo quando este lhe descreve as cidades visitadas em suas missões diplomáticas, mas o imperador dos tártaros certamente continua a ouvir o jovem veneziano com maior curiosidade e atenção do que a qualquer outro de seus enviados ou exploradores. Existe um momento na vida dos imperadores que se segue ao orgulho pela imensa amplitude dos territórios que conquistamos, à melancolia ao alívio de saber que em breve desistiremos de conhecê-lo e compreendê-los, uma sensação de vazio que surge ao calar da noite... Somente nos relatórios de Marco Polo, Kublai Khan conseguia discernir; através das muralhas e das torres destinadas a desmoronar [...] O engenhoso estrangeiro improvisava pantomimas que o soberano precisava interpretar: uma cidade era assinalada pelo salto de um peixe que escapava do bico de um camarão para cair numa rede... As suas eram narrativas mais precisas e minuciosas que o grande Khan podia desejar, e não havia questão ou curiosidade à qual não respondessem... O novo dado ganhava um sentido daquele emblema e ao mesmo tempo acrescentava um novo sentido ao emblema. [...] Mas o que Kublai considerava valioso em todos os fatos e notícias referidos por seu inarticulado informante era o espaço que restava em torno deles, um vazio não preenchido por palavras. (CALVINO, 1990, p. 9).

O espaço em torno de Kublai e Marco Polo, que ele diz não ser preenchido por palavras, pode ser compreendido como um Spielraum (GAGNEBIN, 2012). Eles se inserem no espaço de jogo em que as palavras funcionam como coadjuvantes, permitindo que, anterior a elas, a 
brincadeira direcione as ações e permita o experimentar de ideias e emoções. Depois dessas vivências iniciais, as palavras podem ser trabalhadas para que encontrem formas que expressem o que foi vivenciado. Então, quando o espaço de experimentar é proposto numa metodologia participativa, tanto o educando quanto o educador podem experimentar intensamente o processo de ensino-aprendizagem na leitura. Processos esses que envolvam a efetiva alfabetização daqueles que ainda não a conseguiram.

Por conseguinte, percebemos o quanto a leitura se constrói à medida que a experimentamos e possibilitamos aos outros essa experiência. A ausência da experimentação traz ao homem uma pobreza que paralisa qualquer tipo de narrativa, comunicação e trabalho. Benjamin (1994), no seu livro "Magia e técnica, arte e política", no capítulo "Experiência e pobreza", coloca que a pobreza de experiência não é privada, mas de toda a humanidade trazendo consigo a barbárie embutida. Ele expõe também um conceito novo e positivo de barbárie como resultante dessa pobreza de experiência: "ela o impele a partir para frente, a começar de novo, a contentar-se com pouco, a construir com pouco, sem olhar nem para a direita nem para a esquerda" (BENJAMIN, 1994, p. 116). As colocações de Benjamin dos anos 40, infelizmente, continuam contemporâneas, quando a comunicação é limitada tecnologicamente aos mesmos que sempre tiveram acesso aos instrumentos de comunicação. "Abandonada, sem teto, numa paisagem diferente em tudo, exceto nas nuvens, e em cujo centro, num campo de forças de correntes e explosões destruidoras, estava o frágil e minúsculo corpo humano" (BENJAMIN, 1994, p. 115).

Se para Benjamin a "pobreza de experiências" tem a ver com a dificuldade de intercambiarmos sabedorias que nascem do trabalho e das vivências, dos desafios e das contradições individuais e sociais, o isolamento forçado pela pandemia do covid-19, neste ano de 2020, amplia brutalmente a interrupção da comunicação de experiências, tornando a vida coletiva mais pobre, pois reduz os canais de trocas. Nesse caso, criar ambientes de leitura que sejam também espaços de expressão literária pode ajudar na libertação dessa experiência de isolamento que vivemos por conta dessa pandemia que tanto nos deixa isolados. Diante de tudo isso, da pobreza de experiência no compartilhar com o outro, devido ao distanciamento imposto pela pandemia, podemos perguntar: será então que é possível fazer educação sem escola? Tião Rocha inaugurou uma escola debaixo de uma árvore, na cidade de Curvelo. Hoje, a escola da vida funciona dentro dos lares fechados e extremamente protegidos por soluções desinfetantes. No entanto, essa escola dentro de casa precisa de uma metodologia onde a mediação do professor sistematize a aprendizagem através do diálogo. Porque essa forma online de educação 
que já nos distancia fisicamente das pessoas, não deve distanciar o diálogo e sim provocá-lo, pois não é instrução, mas sim educação (ROCHA, 2014).

A crise econômica está diante da porta, atrás dela está uma sombra, a próxima guerra. A tenacidade é hoje privilégio de um pequeno grupo dos poderosos, que sabe Deus não são mais humanos que os outros; na maioria bárbaros, mas não no bom sentido. Porém os outros precisam instalar-se, de novo e com poucos meios. São solidários dos homens que fizeram do novo uma coisa essencialmente sua, com lucidez e capacidade de renúncia. (BENJAMIN, 1994, p. 119).

\section{CAPTURADA POR UM PROJETO DE EXTENSÃO PARA UMA FORMAÇÃO NO MESTRADO}

Pelo exposto, o projeto "Leitura e identidade no ambiente escolar" se insere num campo de batalha, onde os bárbaros disputam o território com a educação. Militarização e pobreza desqualificam o trabalho educacional brasileiro através do discurso pautado numa leitura sem identidade e vazia de um território onde as experiências acontecem.

Ler é pensar e tocar a materialidade histórica de uma obra literária, cinematográfica ou de qualquer outra expressão estética. Assim, as lutas sociais assumem o simbólico como um campo de batalha, um território em disputa, é essa a proposta das ações do Grupo de Educação Multimídia apresentadas. (MAIA, 2017, p. 3).

Essa definição de leitura oferecida pelo professor Paulo Maia no seu texto, no qual relata sua experiência de trabalho numa oficina de leitura e produção de imagem crítica realizada numa escola do município de Niterói, contribui para estruturar o referido projeto que busca como produto técnico a criação de um laboratório de leitura. É necessário, portanto, ampliar o conceito de leitura dentro de uma perspectiva histórica, estética e social. Levando-se em conta o que Freire (1981, p.76) afirma sobre a leitura no seu livro "Pedagogia da Esperança", "Ler um texto é algo sério. É coisa de sujeito crítico, humilde e determinado." Podemos então perceber o quanto o conceito de leitura amplia as possibilidades e realidades. Além disso, Freire (2017, p. 9) também diz no livro "A importância do ato de ler" que "a leitura do mundo precede a leitura da palavra, linguagem e realidade se prendem dinamicamente". Formulo assim como conceito de leitura a apropriação do homem de sua identidade pertencente a um local dotado de potencialidades que lhe permitam transformar toda e qualquer linguagem em sentido. Ler é apropriar-se de habilidades que permitam uma interferência crítica. Temos sobre esse conceito 
a ideia que Cubero $^{6}$ (1980) traz de uma produção de sentido trabalhada com a participação efetiva visando não apenas informação, mas um trabalho ativo por parte dos estudantes.

O trabalho que o projeto desenvolve tem como matriz a noção de trabalho como princípio educativo (SAVIANI, 2007). O argumento do projeto surgiu a partir de uma oficina de leitura e produção audiovisual oferecida pelo professor Paulo Maia e pelo Grupo de Educação e Multimídia na escola de $1^{\circ}$ e $2^{\circ}$ ciclos do fundamental em que eu trabalho. "Diríamos, pois, que no ponto de partida a relação entre trabalho e educação é uma relação de identidade. Os homens aprendiam a produzir sua existência no próprio ato de produzi-la" (SAVIANI, 2007). Proponho, então, no campo de trabalho na escola, a criação de um laboratório de leitura, que acontece mediante o estudo de metodologias de leitura no ambiente escolar envolvendo os professores no diálogo sobre a elaboração dessas formas e maneiras de trabalho, apresentando como a literatura pode ser um ambiente para, não só trabalhar o sensível, mas também a alfabetização, principalmente daqueles alunos que ultrapassaram a idade-série e se encontram dentro das salas de aula desmotivados.

O projeto busca uma alfabetização que possa ser pensada como um processo que ocorre na e por meio da experimentação, no ato da valorização do conhecimento do educando, das suas fases de desenvolvimento e na ação empreendida por ele quando lhe é proposto um trabalho que faça sentido. Esse trabalho não é aquele enfadonho que se atém somente na leitura mecânica para mostrar se o estudante lê corretamente e se a pronúncia das palavras está correta. O objetivo do LIDE é estimular a leitura nas entrelinhas, o que se busca é relacionar as ideias do texto e usar de forma crítica aquilo que cada um consegue visualizar dentro do seu ponto de vista, de onde ele enxerga o mundo. Investigo como a leitura literária pode ser estimulante nos dias de hoje, onde a tecnologia dos recursos da informática e internet têm capturado as nossas crianças e adultos numa alienação total. A intenção não é combater o uso dos recursos tecnológicos em sala de aula, mas direcioná-la para um trabalho motivador e criativo, quando, por exemplo, a conexão com a internet disputa atenção com a aula, proponho um trabalho de tradução dos clássicos literários para uma nova linguagem, pretendo estimular a tradução intersemiótica na sala de aula. Assim, podemos ler um texto e a partir da construção de um roteiro produzir um vídeo, ou melhor, fazer cinema, trabalhando com as variadas demandas

\footnotetext{
${ }^{6}$ José Cubero foi professor de psicopedagogia e de apreciação cinematográfica da Universidad de la Habana. Deu aula em quase toda a América, na URSS, na Alemanha Oriental. Chegou no Brasil em 2002, trabalhou na Universidade Federal de Juiz de Fora, na Estácio e, por fim, na Universidade Federal do Rio de Janeiro, onde ajudou a criar o GEM, a Escola de Pescadores de Macaé, o Instituto Politécnico da UFRJ em Cabo Frio, o Núcleo Interdisciplinar para o Desenvolvimento Social - Nides/UFRJ, e, em especial, o mestrado profissional e a linha de pesquisa Trabalho e Formação Politécnica, no qual realizo esta pesquisa.
} 
técnicas da linguagem. O objetivo central dessas atividades de tradução entre linguagens é levar os estudantes ao trabalho coerente com a contemporaneidade, com o sensível e necessário ao homem. No que se refere à literatura, tomando as palavras de Candido no seu livro, Vários Escritos.

\begin{abstract}
A Literatura confirma e nega, propõe e denuncia, apoia e combate, fornecendo a possibilidade de vivermos dialeticamente os problemas. Por isso é indispensável tanto à literatura sancionada quanto a literatura proscrita; a que os poderes sugerem e a que nasce dos movimentos de negação do estado de coisas predominantes (CANDIDO, 2011, p.177).
\end{abstract}

No ano de 2019, os alunos da Escola Municipal Professor Marcos Waldemar de Freitas Reis no quarto ano do ensino Fundamental, desenvolveram um vídeo como produto de uma leitura literária. A turma, que já estava desenvolvendo um trabalho de Ciências e Geografia sobre "Desperdício e poluição ambiental”, leu um capítulo do livro "As cidades invisíveis", de Ítalo Calvino. O texto apresentava a cidade de Leônia, com seus moradores que, ao consumir de forma excessiva, desperdiçavam num ciclo vicioso, gerando poluição e cataclismo. Inicialmente, a história geral do livro foi apresentada aos estudantes, que se concentraram na discussão da temática trazida pelo capítulo. Em seguida, eles elaboraram um roteiro com as críticas feitas por eles e traduziram a história de Leônia por meio de um vídeo. Após a elaboração desse roteiro, a turma foi dividida em grupos de trabalho para a produção de uma maquete. Finalizada a maquete, os alunos se revezaram para fotografar e arrumar cada cena na maquete, o que depois seria organizado por um programa de edição de animação. Além da minha participação, também atuaram os alunos e a estagiária de suporte de informática da escola, Daniela da Costa Rosas Rocha. Ela foi primordial nessa edição e no trabalho em conjunto nos vários dias em que aconteceram todas as ações. Por fim, os alunos elaboraram uma estrutura e por meio dela explicitaram a sua visão de mundo.

De fato, quando elaboram uma estrutura, o poeta ou o narrador nos propõe um modelo de coerência, gerado pela força da palavra organizada. Se fosse possível abstrair o sentido e pensar nas palavras como tijolos de uma construção, eu diria que esses tijolos representam um modelo de organizar a matéria, e que enquanto organização eles exercem papel ordenador sobre a nossa mente. Quer percebamos claramente ou não, o caráter de coisa organizada da obra literária tornar-se um fator que nos deixa mais capazes de ordenar a nossa própria mente e sentimentos; e, em consequência, mais capazes de organizar a visão que temos do mundo. (CANDIDO, 2011, p. 179).

Neste mesmo ano, quando na escola somente se encontravam os professores, tendo os alunos já ingressados para o recesso escolar do final de ano, apresentei juntamente com a 
estudante da Escola de Belas Artes da UFRJ Mei Maia, aos professores, uma oficina chamada "Oficina das teolomitas"7. Tal oficina teve como objetivo a "formação de leitores, garantindo uma forma de ler com autonomia técnica. Autonomia que dá habilidades, condições críticas, condições de olharem para além da decodificação dos padrões de leitura que já dispõem" (MAIA, 2019). Assim, conceito e forma foram colocados na roda de discussão e analisados entendendo o processo de leitura. As professoras debateram sobre tal processo: decodificação e compreensão das partes e como essas partes compõem um sistema. O que se destacou é a semelhança dessa atividade inicial com processos iniciais de leitura. Depois, numa segunda atividade, encaminhamos a leitura com base na observação, na experimentação e identificação de diferentes imagens. Essa oficina permitiu direcionarmos três aspectos: as metodologias participativas, a possibilidade multidisciplinar e a crítica. Então, a partir da oficina percebeu-se que a leitura parte da observação de padrões de estruturas, os quais ao serem identificados possibilitam desenvolver habilidades e perspectivas críticas que superam a simples decodificação. Foi possível aos professores observarem padrões em várias estruturas: artísticas, matemáticas etc. Eles também discutiram sobre uma educação sensível, que se desconecta assim do ensino fragmentado e especializado (DUARTE, 2000, p. 174-175).

O que constitui clara indicação de que a educação centrada sobre faculdades humanas isoladas, como o intelecto ou a sensibilidade, só podem mesmo resultar em indivíduos dotados de um profundo e básico desequilíbrio: ao sensível e ao inteligível devem ser propiciadas condições equânimes de desenvolvimento, sob pena da produção de seres humanos arraigadamente desequilibrados, como soe acontecer nos dias em que vivemos. O que implica num reconhecimento do erro — prático e conceitual - cometido pela moderna sociedade industrial ao dirigir seus esforços educacionais em prol da formação de especialistas, cujo campo de atuação se restringe cada vez mais a fatias menores e menores da realidade, sem qualquer preocupação com o mundo amplo no qual vivem e atuam.

Portanto, este projeto, assim como a lógica da pedagogia do sabão ${ }^{8}$ de Tião Rocha, levou à apropriação e adaptação de tecnologias de baixo custo sendo replicadas pelo coletivo

\footnotetext{
7 Teolomita é um termo criado pelo professor Cubero para identificar estruturas que seguem um padrão de composição. Cubero usava peças de encaixe que adaptamos com lego para discutir a diferença entre os aspectos essenciais e os gerais em distintas estruturas.

${ }^{8}$ A Pedagogia do Sabão é resultante do aprender-fazendo, partindo do saber coletivo, recuperando práticas tradicionais e incorporando novos valores. Busca a auto-sustentabilidade, o desenvolvimento integral e a formação solidária das pessoas envolvidas. Utiliza os saberes e fazeres culturais dos participantes como matéria-prima de ações pedagógicas, trabalhando com soluções e alternativas que integram satisfação econômica, valores humanos e culturais, compromisso ambiental e empoderamento comunitário. A lógica da pedagogia do sabão nada mais é do que a apropriação e adaptação de tecnologias de baixo custo ou de custo zero, que podem ser replicadas em qualquer comunidade. Disponível em: http://www.cpcd.org.br/historico/pedagogias-do-cpcd/. Acesso em: 16 jun. 2015. (2015 apud SEVERO, 2016).
} 
(SEVERO, 2016). Buscando por meio da criação do laboratório de leitura permitir aos estudantes, partindo do sensível, perceber que são capazes de fazer algo. Esse é o "empodimento" necessário a uma proposta para formação de leitores.

\section{CONCLUSÃO}

Esse artigo buscou apresentar o projeto "Leitura identidade no ambiente escolar", identificando a metodologia pesquisada por meio do LIDE. Revelando a intenção do laboratório em contribuir com a diminuição da dificuldade de leitura, dos estudantes, através de oficinas de leitura literária. O objetivo desta pesquisa fundamenta-se nas altas taxas de analfabetismo dos estudantes nas escolas de Ensino Fundamental. Nelas encontramos muitos alunos no quinto ano com extremas dificuldades de leitura e sem aquisição do código alfabético. Os dados abaixo fazem referência à tabela de níveis de alfabetização funcional realizada pela UNESCO, apresentada na primeira seção deste artigo.

O IBOPE identificou, em pesquisa de $2003,68 \%$ de analfabetismo funcional na população brasileira acima de 15 anos de idade - 30\% no nível 1 e $38 \%$ no nível 2. Nesse quadro, possuiríamos hoje mais de 130 milhões de analfabetos funcionais. Entretanto, outras pesquisas vêm revelando índices menores de analfabetismo funcional, tanto no nível 1 quanto no nível 2. Por exemplo, o IBGE identificou, em 2014, 27\% de analfabetos funcionais na população jovem e adulta. Tamanha disparidade estatística certamente decorre de diferenças metodológicas na condução da pesquisa e não de um súbito aumento extraordinário do letramento da população em apenas uma década. (KENEDY, 2018, p. 90).

Portanto, a necessidade de formarmos leitores fica evidente diante de estudos e pesquisas que comprovam o quanto os estudantes brasileiros necessitam de propostas pedagógicas para que eles desenvolvam habilidades de leitura. Mas não somente as pesquisas me motivaram na escrita e prática do projeto, e sim o chão da escola que me direcionava a buscar propostas. Ao receber todo ano um ou dois alunos no quarto e quinto ano que não liam, me angustiava levando-me a caminhos que não surtiam efeito, pois me faltava o caminho da metodologia participativa e do trabalho politécnico que busca na autonomia desses estudantes o seu engajamento. Eu, enquanto professora, precisava de formação para entender como o processo de leitura acontecia para assim buscar uma metodologia e experimentá-la, porque professores precisam aprender assim como todo ser humano, vivemos no constante aprendizado. Entendi que precisava me tornar uma educadora-aprendiz, aprender junto com os alunos. 
Foi nesse momento que o Grupo de Educação e Multimídia da UFRJ representado pelo professor Paulo Maia foi visitar a escola levando um trabalho de parceria, e apresentou metodologias participativas como sugestão. Dessa parceria o intercâmbio entre a escola e a universidade se efetivou levando a escola também à universidade, por meio da minha entrada no mestrado profissional em Tecnologia social no NIDES-UFRJ na linha de pesquisa Trabalho e Formação Politécnica. O que vem gerando o desenvolvimento do projeto com a estruturação de um laboratório de leitura inspirado no Grupo de Educação Multimídia

Assim, o artigo apresenta o caminho dessa pesquisa que procura na leitura literária, entendendo o potencial e a importância dela na formação humana, um trabalho junto aos recursos audiovisuais propondo uma tradução entre linguagens, para contribuir com a solução de um problema que atinge os estudantes brasileiros: a falta ou dificuldade na leitura, identificado pelos vários instrumentos de pesquisa e avaliação.

Diante do que foi mencionado, a implementação do LIDE na escola já trouxe o desenvolvimento de duas oficinas de leitura: uma, com os estudantes propondo um trabalho de tradução intersemiótica e outra, com os professores buscando formação para um olhar através das metodologias participativas. Esta última possibilitou que um grupo de professores experimentasse, por meio das oficinas lúdicas, como são encontrados padrões na leitura e também perceber a necessidade de metodologias que possibilitem o trabalho multidisciplinar e crítico. A primeira oficina propôs a adaptação do texto de Ítalo Calvino para trabalhar a leitura, embora contasse com um aluno com dificuldade de leitura o engajamento dele foi possível, porque o trabalho lhe garantiu propor ideias, construir cenários e elaborar críticas. Além disso, a oficina resultou na produção de um vídeo de animação, a apresentação com exposição verbal sobre o argumento do filme por alguns estudantes a um grupo de estudantes neozelandeses que visitavam a escola buscando intercâmbio de informações e conhecimento sobre a realidade educacional no Brasil.

Atualmente, o projeto tenta articular suas ações remotamente, devido à pandemia da COVID-19 que fechou as escolas no país. Porém, com o início das aulas remotas e a proposta de um grupo de professoras para trabalhar por meio de projetos a serem implementados através de uma plataforma digital, o LIDE busca junto a essas professoras mediar esses projetos por meio da metodologia participativa. O que se conseguiu com todas as limitações da exclusão digital foi trabalhar de forma coletiva e multidisciplinar, elaborando propostas de projetos temáticos que vêm contando com parcerias para dialogar. Uma dessas parcerias se estabeleceu com o Museu de Arqueologia de Itaipu por meio de um projeto de Educação Ambiental no qual 
as professoras articularam Língua Portuguesa e Educação Patrimonial. Outra parceria conquistada e efetivada está acontecendo junto aos professores e estudantes de Grego Clássico da Universidade Federal do Rio de Janeiro (UFRJ). A proposta é a experimentação de um projeto de estudo dos mitos propondo um olhar sobre os heróis gregos a partir de suas virtudes, relacionando-os com virtudes necessárias à humanidade e a recuperação das línguas e da literatura clássica como importantes para a formação do homem.

Logo, a partir das questões da "experiência e pobreza" e do espaço de experimentar, se busca criar um espaço físico e virtual, com apropriação tecnológica, criativa e crítica, como prática social e pedagógica contra a deformação reprodutiva da educação bancária e como pesquisa científica atrelada ao chão da escola, garantindo que o ambiente acadêmico, permeado pelo desenvolvimento do conhecimento, possa ser comum também à escola envolvendo os estudantes na participação da construção do conhecimento. Essa é a proposta do LIDE, à qual formação continuada, de uma professora mestranda, se articula.

\section{REFERÊNCIAS}

BENJAMIN, W. Magia e técnica, arte e política: ensaios sobre Literatura e História da cultura. Tradução: Sérgio P. Rouanet. 7. ed. São Paulo: Brasiliense, 1994. 222p.

BRASIL. Lei de Diretrizes e Bases da Educação Nacional. Lei número 9394, 20 de dezembro de 1996.

BRASIL. Secretaria de Educação Fundamental. Parâmetros curriculares nacionais: língua portuguesa. Brasília: SEF, 1997. 144p.

CANDIDO, A. Vários Escritos. 5. ed. corrigida pelo autor: Rio de Janeiro: Ouro sobre Azul, 2011. $272 \mathrm{p}$.

CALVINO, I. As cidades invisíveis. São Paulo: Companhia das Letras, 1990. 151p.

CHEDID, F. H. Tecnologia para o desenvolvimento social: Diálogos Nides-UFRJ, In: MAIA, Paulo. Oficina de Leitura e produção de imagem crítica: uma experiência de trabalho como princípio educativo. Marilia: Lutas Anticapital, 2018. 457p.

CUBERO, J. Arquivo Pessoal. 1980.

DUARTE, J. F. J. O sentido dos sentidos: A educação (do) sensível. 2000. 234 p.

Dissertação (Mestrado) - Faculdade de Educação, Universidade Estadual de Campinas, Campinas, 2000.

FREIRE, P. A importância do ato de ler. São Paulo: Cortez, 2017. 
FREIRE, P. Pedagogia da Esperança: um reencontro com a Pedagogia do Oprimido. Rio de Janeiro: Paz e Terra, 2013.

FREIRE, P. Pedagogia do Oprimido. 69. ed. Rio de Janeiro/São Paulo: Paz e Terra, 2019. 256p.

GAGNEBIN, Jeanne-Marie. "Brecht e Benjamin: peça de aprendizagem e ordenamento experimental”. Viso: Cadernos de estética aplicada, v. 6, nº 11 (jan-jun/2012), p. 145-151. Disponível em: http://revistaviso.com.br/article/129. Acesso em: 11 ago. 2020.

KENEDY, E. O problema do analfabetismo funcional no brasil sob uma análise psicolinguística. In: MAIA, Marcos: Psicolinguística e Educação. Campinas: Mercado de Letras: EDUFRR, 2018. p. 81-102.

MAIA, P. Travessias: Palavra-Imagem. Revista Terceira Margem - Revista do Programa de Pós-Graduação em Ciência da Literatura, Universidade Federal do Rio de Janeiro, Rio de Janeiro, ano XXIV, n. 44, p. 32-49, set./dez. 2020.

MAIA, P. Arquivo pessoal. 2017.

PESSOA, F. Livro do Desassossego. São Paulo: Companhia das Letras, 2006. 559p.

TIÃO ROCHA. Educação acontece em todo lugar. Palestra, 6 nov. 2014. 1 vídeo.

Disponível em: https://www.youtube.com/watch?v=PjQqjz01H-M. Acesso em: 15 ago. 2020.

SAVIANI, D. Trabalho e educação: fundamentos ontológicos e históricos. Revista

Brasileira de Educação, Universidade Estadual de Campinas, Faculdade de Educação, v. 12 n. 34, jan./abr. 2007.

SAVIANI, D. O choque teórico da Politecnia. Trab. educ. saúde (online). Rio de Janeiro 2003, v. 1, n. 1, p. 131-152, mar. 2003. Disponível em:

https://www.scielo.br/pdf/tes/v1n1/10.pdf. Acesso em: 14 dez. 2020.

SEVERO, F. G. TICs e TACs: o refazimento de softwares e engenheiros no limiar entre as ciências e os segredos. 2026. 164 p. Dissertação (Mestrado) - UFRJ/COPPE/Programa de Engenharia de Sistemas e Computação, Universidade Federal do Estado do Rio de Janeiro, Rio de Janeiro, 2016. 